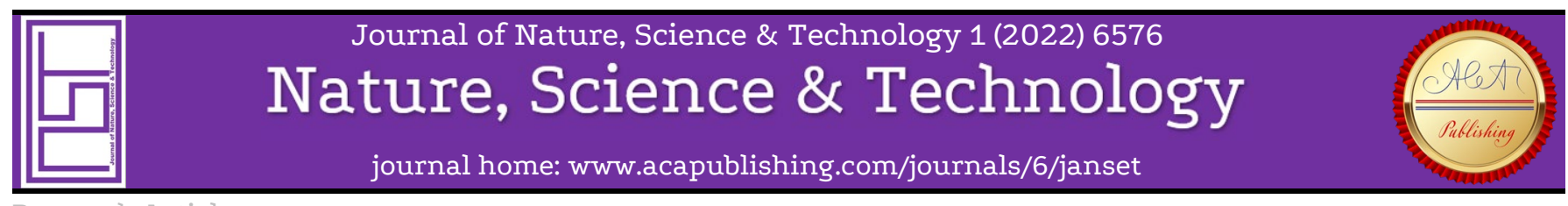

Research Article

\title{
Analysis of the Effect of Climate Change on Flood Flows of Kemer Ağva River, Antalya
}

Tuğba ÖZKOCA*,'(D), Aslı ÜLKE KESKİN ${ }^{2}$ (D)

${ }^{1}$ MSc., State Hydraulic Works, 13th Regional Directorate, Antalya, Turkey

2 Assoc. Prof., Department of Civil Engineering, Faculty of Engineering, Ondokuz Mayıs University, Samsun, Turkey

\section{Keywords}

\section{Basin;}

Flood Discharge;

Global Climate Model;

Climate Change Impacts;

Antalya

\begin{abstract}
The environment and atmosphere are largely polluted due to increased urbanization, especially greenhouse gases from industrial and residential areas, and the trend of warming air on a global scale is increasing. In the event that global climate change persists for many years, it is expected that there may be significant increases in the severity, frequency and activity of hydrological natural disasters such as floods caused by these events, as well as extreme weather events. In recent years, Turkey has seen an increase in summer temperatures caused by climate change, a decrease in winter precipitation, and sudden and heavy rains and flood. Especially in the Western Mediterranean basin, heavy rainfall and flood events have started to be seen frequently due to climatic changes. In this study, current flood flow rates in Antalya Kemer Agva Stream and flood flow rates of 2050, 2075 and 2100 projections of HadGEM2-ES, MPI-ESM-MR and CNRM CM 5.1 climate models outputs were determined according to RCP 4.5 and RCP 8.5 scenarios. With this study, it has been revealed that the flood flows in the Kemer Agva basin will increase in the period until 2050 compared to the current situation, and will decrease in the periods of 2075 and 2100.
\end{abstract}

\section{Introduction}

The destruction that humanity has done and is doing on land and water in the last century has significantly deteriorated the composition of soil and water, as well as air [1]. Apart from human activities, another reason for the increase in floods in recent years is climate change and it is predicted that there will be an increase in the amount of precipitation per unit area in a short time due to the effects of climate change. Billions of dollars in infrastructure and property due to natural disasters such as floods damage and hundreds of people die every year [2]. The devastating effects of floods can be reduced with the right measures to be taken in a timely manner. Direct and indirect effects of floods; depending on the intensity of the floods, the time of occurrence, the duration and the domain.

Current research indicates that there will be a significant future increase in heavy rainfall events in many regions, including some of the areas where reductions in average precipitation are expected. As a result, the increased flood risk will create problems in society, physical infrastructure systems and water quality. It is likely that around $20 \%$ of the world's population will live in areas where the potential for river flooding may increase by 2080. Increases in the frequency and severity of floods are expected to adversely affect sustainable development [3]. In order to reduce the material and moral damages of floods, good knowledge of the mechanism and taking precautions before arriving required [4].

In the 5th Assessment Report of the Intergovernmental Panel on Climate Change (IPCC), it is stated that the earth has warmed considerably since 1850 and that the last 1400 years in the northern hemisphere, the hottest 30 years have been between 1983-2012. It has been determined that the warming observed between 1951 and 2010 was approximately between $0.6^{\circ} \mathrm{C}$ and $0.7^{\circ} \mathrm{C}$, and the warming observed since the middle of the 20th century was due to a serious human effect [5]. In order to project more accurate climatic conditions, Global Climate Models (GCM) from the dataset of phase 5 of the Coupled Model Intercomparison Project Phase (CMIP 5) were used for the IPCC
Assessment Report 5 (AR5) in the most recent climate impact studies. In AR5, climate scenarios are classified according to radiative forcing levels RCP 2.6, RCP 4.5, RCP 6 and RCP 8.5 [6].

To determine future flows and flood projections work with higher resolution Regional Climate Models (RCMs) at basins scale. Dynamic scale is the method behind the Regional Climate Model is downsizing. With the downscaling method, observations or low resolution images Regional or local details are captured from numerical simulations [7]. Numerical analysis has recently become the most basic tool used in flood modeling [8].

In this study, using RegCM4.3 as the regional climate model in the project, the precipitation forecasts of the basin in the coming years were studied by considering the 2050, 2075 and 2100 projections of the HadGEM2-ES, MPI-ESM-MR and CNRM CM 5.1 climate models outputs according to the RCP 4.5 and RCP 8.5. The flood flow rates obtained according to the estimation data were compared with the current flood flow values.

\section{Study Area and Data}

Known as the capital of tourism in Turkey, Antalya is the country's fifth largest city. According to the end of 2020 data, it has a population of 2.5 million [9]. Antalya city center covers an area of approximately $20177 \mathrm{~km} 2$. The location of Antalya in Turkey is shown in Figure 1.

The basin, which is considered in the study, is located in the Çamyuva neighborhood of Kemer District of Antalya. Ağva Stream basin is located within the Western Mediterranean Basin. Deli River, the main branch of Ağva Stream, originates from Tahtalı Mountains. It is formed by the combination of Çatak Stream, Gürleve Stream and Sumakseniri Stream.Ağva Stream basin is located in 1/25 000 scaled $024-c 2 / c 3$ and $025-d 1 / d 4$ maps. The precipitation area is surrounded by these maps and is $136.28 \mathrm{~km}^{2}$. 


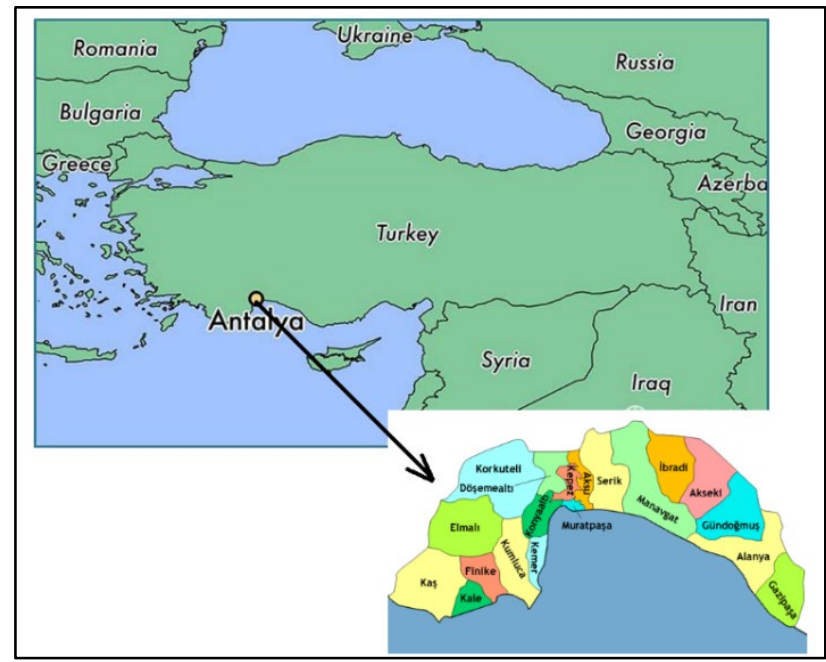

In the study, precipitation stations with sufficient time and reliable observation value were determined by the Thiessen method according to their rate of representing the basin. According to the Thiessen study, there are Ovacik MI, Altınyaka MI and Kemer MI in the precipitation area basin (Figure 2 ). The daily maximum precipitation data of these stations to be used in the study were obtained from the General Directorate of Meteorology.

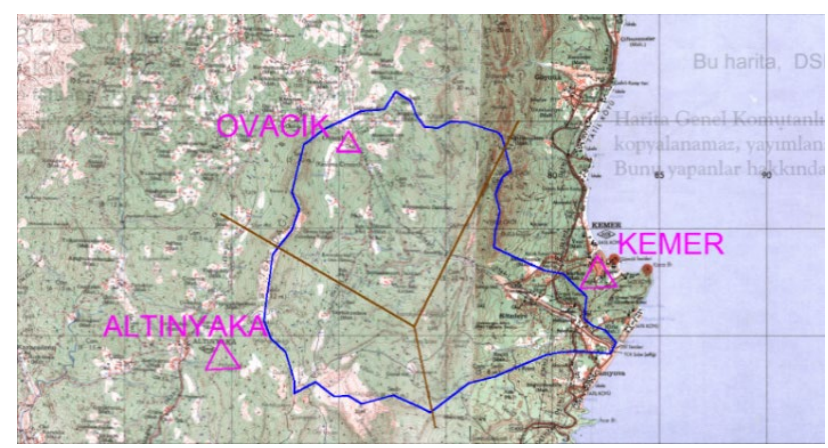

The model data used in the study were obtained from the General Directorate of Water Management. Future climate simulations obtained for representative concentration scenarios RCP4.5 and RCP8.5 were evaluated against the 1971-2000 reference period. HadGEM2-ES and CNRM-CM5.1. Today's simulations for the model were carried out for the period of January 1960-December 2000 and a total of 41 years of simulation were made for today's conditions. However, coupler simulations were started in 1970, since the CMIP5 archive has been providing the simulations of the MPI-ESM-MR model since 1970(Table 1).

Table 1. List of Models

\begin{tabular}{ccc}
\hline Model & Scenarios & Period \\
\hline \multirow{2}{*}{ HadGEM2-ES } & Referans & $1960-2000$ \\
& RCP 4.5 & $2015-2100$ \\
MPI-ESM-MR & RCP 8.5 & $2015-2100$ \\
& Referans & $1970-2000$ \\
& RCP 4.5 & $2015-2100$ \\
CNRM-CM5.1 & RCP 8.5 & $2015-2100$ \\
& Referans & $1960-2000$ \\
& RCP 4.5 & $2015-2100$ \\
& RCP 8.5 & $2015-2100$ \\
\hline
\end{tabular}

\section{Methodology}

The methodology of this study consists of three main parts:

a) In the calculation of the flood flow rates in Kemer Ağva Stream, first, the basin characteristics of the Ağva River were determined. Then, the stations affecting the basin, the instantaneous maximum precipitation amounts of these stations per year, the probability distribution functions most used in hydrology; calculated using Normal (Gaussian), Lognormal, Gumbel, and Log-Pearson Type-3 (Gamma) distributions.

b) There are more than one method in flood calculation. In each method, different assumptions are made according to the characteristics of the basin. Therefore, calculations for the same basin may yield different results. Method applications according to the size of the basin are given in Table 2. DSI Synthetic Method was used in the study.

Table 2. Methods calculating flow rate [10]

\begin{tabular}{ll}
\hline Methods & Application Area $(\mathrm{A})\left(\mathrm{km}^{2}\right)$ \\
\hline Rational Method & $\mathrm{A}<5 \mathrm{~km}^{2}$ \\
Mockus Method & $5 \mathrm{~km}^{2}<\mathrm{A}\left(\mathrm{km}^{2}\right)<50 \mathrm{~km}^{2}$ \\
DSI Synthetic Method & $10 \mathrm{~km}^{2}<\mathrm{A}\left(\mathrm{km}^{2}\right)<1000 \mathrm{~km}^{2}$ \\
Synder Method & $\mathrm{A}>1000 \mathrm{~km}^{2}$ \\
\hline
\end{tabular}

c) After calculating the current flood flow rates in the Ağva River, the flood flow rates of the 2050, 2075 and 2100 projections of the HadGEM2-ES, MPI-ESM-MR and CNRM CM 5.1 climate models outputs according to RCP 4.5 and RCP 8.5 were determined for the estimation of the future flood flows.

\subsection{Determination of Instantaneous Maximum Precipitation Per Year}

Normal distribution

Determining a theoretical probability density function $f(x)$ that fits the frequency histogram obtained by frequency analysis of a statistical sample is a common problem in statistical applications. It is seen that some functions in a certain form fit the distribution of many random variables [11]. $\mathrm{X}$ is the probability density function of the normal random variable,

$f(x)=\frac{1}{\sigma_{x} \sqrt{2 n}} \exp \left[-\left(x-\mu_{x}\right)^{2} / 2 \sigma_{x}^{2}\right]-\infty<x<\infty$

$\mathrm{Eq}(1)$

Normal distributed variables are less common in hydrology than in other fields [11]

\section{Log-Normal distribution (2 parameter)}

If the logarithm of the variable $\mathrm{x}$ is normally distributed, the distribution of $\mathrm{x}$ is lognormal. The lognormal distribution is widely used in hydrology because a log normal distributed variable has only positive values and its distribution is skewed.

$\mathrm{Y}=\mathrm{X}_{\mathrm{ort}}+\mathrm{k} \sqrt{\left(\frac{\sum \mathrm{x}^{2}}{\mathrm{~N}}-\left(\frac{\sum \mathrm{x}}{\mathrm{N}}\right)^{2}\right)\left(\frac{\mathrm{N}}{\mathrm{N}-1}\right)}=\mathrm{X}_{\mathrm{ort}}+\mathrm{kS} \mathrm{n}$

$\mathrm{Eq}(2)$

Calculating $\mathrm{Y}=\ln (\mathrm{X})$, precipitation or flow rates for various recurrence times are calculated by Equation 2[13-14-15].

\section{Log-Normal distribution (3 parameter)}

If the lower bound of the variable in the log normal distribution is a value other than zero, a 3-parameter Log Normal distribution is obtained by substituting $\mathrm{x}-\mathrm{y}$ for $\mathrm{x}$ in Equation 2[12].

\section{Pearson Type-3 distribution}

The probability density function of the Pearson Type 3 distribution is as given in Equation 3. 
$f(x)=|\beta|\left[\beta(x-\xi]^{\alpha-1} \frac{\exp [\beta(x-\xi]}{\Gamma(\alpha)} \beta>0 \quad \xi=0\right.$

It is not possible to define a probability mass function for the Pearson Type 3 distribution. It is necessary to make use of tables or admissions [16].

\section{Log-Pearson Type-3 distribution}

The Log-Pearson Type-3 distribution is similar to the log normal distribution. It is the most commonly used distribution type in flood analysis. The parameters of the variables are found as follows [17].

$E\left[Y^{r}\right]=e^{r^{\xi}}\left(\frac{\beta}{\beta-r}\right)^{\alpha}$

$\mu_{\mathrm{Y}}=\mathrm{e}^{\xi}\left(\frac{\beta}{\beta-1}\right)^{\alpha}$

$\sigma_{\mathrm{Y}}^{2}=\mathrm{e}^{2 \xi}\left[\left(\frac{\beta}{\beta-2}\right)^{\alpha}-\left(\frac{\beta}{\beta-1}\right)^{2 \alpha}\right]$

After analyzing the stations according to all distribution types, it is determined, which distribution is suitable with the Kolmogorov Simirnov test.

\subsection{Determination of Flow Discharge}

Hydrograph analysis and unit hydrograph and basin parameters cannot be obtained in basins that do not have flow observation stations with sufficient time and reliability. Synthetic methods have been developed to determine hydrographs of such basins based on their basin size, shape and slope.

\section{DSI Synthetic Method}

The steps to be followed in the DSI Synthetic method;

a) The drainage area of the basin $(\mathrm{A})$ and the longest stream branch (L) are drawn.

b) The longest stream branch is divided into 10 equal parts and the harmonic slope of the streambed is determined (Equation 7).

$S=\left(\frac{10}{\sum \frac{1}{\sqrt{s}}}\right)^{2} \quad l=\frac{L}{10}(\mathrm{~m})$

c) The distance $\left(L_{c}\right)$ of the projection of the center of gravity of the basin to the downstream point of the stream is determined.

d) For the calculation of incremental flows in the DSI synthetic unit hydrograph method; the areal distributions of precipitation are determined from the graphics prepared for our country.

e) While performing the analysis in the DSI Synthetic (Superposed) method, the flow yield (qp; lt/s/mm/ $\mathrm{km} 2$ ) and the peak flow amount (Qp) that a 2-hour precipitation will bring from the unit area, which gives the unit flow height, are calculated(Equation 8).

$\mathrm{q}_{\mathrm{p}}=\frac{414}{\mathrm{~A}^{0,225}\left(\mathrm{~L}^{*} \frac{\mathrm{I}_{\mathrm{C}}}{\mathrm{S}^{0,5}}\right)}$

$$
\mathrm{Q}_{\mathrm{p}}=\mathrm{A}^{*} \mathrm{q}_{\mathrm{p}}{ }^{*} 10^{-3}
$$

f) Calculate the volume $\mathrm{Vb}$ of the unit hydrograph, where $\mathrm{A}$ : precipitation area and ha: unit flow height of $1 \mathrm{~mm}$ (Equation 9).

$\mathrm{V}_{\mathrm{b}}=\mathrm{A} * 10^{3}$

g) The continuation time of the hydrograph (T) and the rise time of the hydrograph $(\mathrm{Tp})$ are calculated (Equation 10).

$\mathrm{T}=3,65 * \frac{\mathrm{V}_{\mathrm{b}}}{\mathrm{Q}_{\mathrm{p}}} \quad \mathrm{T}_{\mathrm{p}}=\mathrm{T} / 5$

$\mathrm{Eq}(10)$

In the DSI synthetic method, if the project downpour duration is taken as a multiple of 2 hours, $\mathrm{T}$ and $\mathrm{T} / \mathrm{Tp}$ should be integers [18].

3.3 Generation of Future Precipitation Data for Kemer Agva Basin

Model data used in the study were obtained from the General Directorate of Water Management. The precipitation data produced by the models for the next years of the station points determined according to the Thiessen polygon from the Kemer Ağva basin were used.

The data provided for use in the study were taken as netCDF extension. In order for these data to be converted to excel format and included in the study, the necessary codes were written in the Python programming language and the transformation was achieved. The codes consist of two parts. In the first part, the data were extracted by taking the raw data and finding the closest point to the desired coordinate. In the second part, the extracted data was arranged and saved in an excel file.

\section{Results and Discussions}

\subsection{Determination of Current Situation Flood Discharges}

River length (L) and Lc values should be determined in the calculations made by DSI Synthetic method for Kemer Ağva River.

While performing the analysis in the DSI Synthetic (Superposed) method, the flow efficiency $\left(\mathrm{q}_{\mathrm{p}}\right)$ and peak flow $\left(\mathrm{Q}_{\mathrm{p}}\right)$ amount that will be brought from the unit area by a 2 -hour precipitation, which gives the unit flow height, are calculated.

$\mathrm{q}_{\mathrm{p}}=\frac{414}{136.28^{0,225}\left(20540^{*}{\frac{9980}{0.027^{0.5}}}^{0.16}\right.}=43.753 \mathrm{l} / \mathrm{s} / \mathrm{km}^{2} / \mathrm{mm}$

$\mathrm{Q}_{\mathrm{p}}=136.28 * 43.753 * 10^{-3}=5.96 \mathrm{~m}^{3} / \mathrm{s} / \mathrm{mm}$

Continuation time of the Hydrograph ( $\mathrm{T}$ ) and rise time of the Hydrograph (Tp);

$\mathrm{T}=3.65 * \frac{136280}{5.96 * 3600}=23 \mathrm{~h} \quad \mathrm{~T}_{\mathrm{p}}=\frac{\mathrm{T}}{5}=4.6 \mathrm{~h}$

DSI Synthetic method unit hydrograph is given in Figure 3 for a unit flow of $1 \mathrm{~mm}$

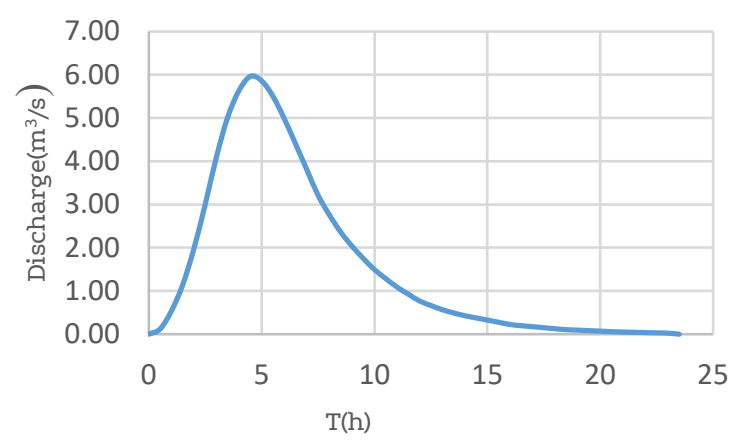

Figure 3 DSI Synthetic Method Unit Hydrograph

The flood flow values calculated according to the DSI Synthetic method are given in Table 3.

Table 3.Iterative Flow Discharges for Agva Basin According to DSI Synthetic Method (m3/s)

\begin{tabular}{lllllll}
\hline Q2 & Q5 & Q10 & Q25 & Q50 & Q100 & Q500 \\
\hline 78.29 & 184.13 & 290.39 & 469.11 & 629.32 & 808.53 & 1167.09 \\
\hline
\end{tabular}

4.2 Determination of Flood Discharges According to Climate Models

RCP 4.5 Scenarios Flood Discharges

According to the RCP 4.5 scenario of HadGEM2-ES, MPI-ESM-MR and CNRM CM 5.1 models, 2050, 2075 and 2100 projections were handled separately and the flood flow rates were calculated using the DSI Synthetic method. Studies for each model are given in separate tables (Table 4). 
Table 4.2050, 2075 and 2100 Projections RCP 4.5 Scenarios Flood Discharges $\left(\mathrm{m}^{3} / \mathrm{s}\right)$

\begin{tabular}{ccccccccc}
\hline Prj & Model & $\mathbf{2}$ & $\mathbf{5}$ & $\mathbf{1 0}$ & $\mathbf{2 5}$ & $\mathbf{5 0}$ & $\mathbf{1 0 0}$ & $\mathbf{5 0 0}$ \\
\hline \multirow{2}{*}{2050} & HadGEM2-ES & 35.86 & 76.58 & 131.7 & 267 & 447.4 & 726.6 & 1138 \\
& MPI-ESM-MR & 36.74 & 82.96 & 143.6 & 283.9 & 457.6 & 707.8 & 1098 \\
& CNRM CM 5.1 & 35.46 & 76.67 & 132.9 & 271.3 & 456.3 & 743.5 & 1166 \\
& & & & & & & & \\
\multirow{2}{*}{ 2075 } & MadGEM2-ES & 33.41 & 75.45 & 127.1 & 235.3 & 354.7 & 513.7 & 781.2 \\
& CNRM CM 5.1 & 31.93 & 72.1 & 123.2 & 232.1 & 353.9 & 517.1 & 789.7 \\
& & & & & & & & \\
& & & & & & & & \\
2100 & MadGEM2-ES & 31.37 & 66.19 & 109 & 198.7 & 298 & 432.8 & 656.8 \\
& MPI-ESM-MR & 34.9 & 72.91 & 118.3 & 212.8 & 318.8 & 463.8 & 702.9 \\
& CNRM CM 5.1 & 31.82 & 66.94 & 110.2 & 200.2 & 299.2 & 432.5 & 655.5 \\
\hline
\end{tabular}

\section{RCP 8.5 Scenarios Flood Discharges}

According to the RCP 8.5 scenario of HadGEM2-ES, MPI-ESM-MR and CNRM CM 5.1 models, 2050, 2075 and 2100 projections were handled separately and the flood flow rates were calculated using the DSI Synthetic method. Studies for each model are given in separate tables (Table 5).

Table 5.2050, 2075 and 2100 Projections RCP 8.5 Scenarios Flood Discharges $\left(\mathrm{m}^{3} / \mathrm{s}\right)$

\begin{tabular}{ccccccccc}
\hline Prj & Model & $\mathbf{2}$ & $\mathbf{5}$ & $\mathbf{1 0}$ & $\mathbf{2 5}$ & $\mathbf{5 0}$ & $\mathbf{1 0 0}$ & $\mathbf{5 0 0}$ \\
\hline \multirow{2}{*}{2050} & HadGEM2-ES & 34.08 & 75.27 & 132.3 & 274.4 & 464.4 & 756.7 & 1189 \\
& MPI-ESM-MR & 36.03 & 82.35 & 147.2 & 307 & 515.7 & 831.8 & 1306 \\
& CNRM CM 5.1 & 36.87 & 79.98 & 134.2 & 262.3 & 433.8 & 710.2 & 1109 \\
& & & & & & & & \\
\multirow{2}{*}{2075} & MadGEM2-ES & 34.21 & 75.37 & 129.4 & 253.1 & 404.8 & 621.6 & 962.3 \\
& MPI-ESM-MR & 33.67 & 71.59 & 120.6 & 231.6 & 366.8 & 562.9 & 869 \\
& CNRM CM 5.1 & 34.29 & 77.73 & 129.3 & 233.7 & 345.6 & 491.5 & 742.2 \\
& & & & & & & & \\
\multirow{2}{2}{2100} & MadGEM2-ES & 33.37 & 69.34 & 114.5 & 213.2 & 329.4 & 494.8 & 757.9 \\
& MPI-ESM-MR & 32.34 & 68.42 & 112.3 & 204.1 & 307.4 & 449.4 & 682.7 \\
& CNRM CM 5.1 & 33.11 & 74.16 & 122.1 & 216.6 & 315.7 & 443.1 & 665.2 \\
\hline
\end{tabular}

\section{Conclusion}

In the analysis of the obtained flood flows between the two scenarios used in each of the three models, it was seen that the difference between the recurrence flows was quite low. For this reason, it was considered appropriate to take the average of the flood flows obtained from the outputs of the three models in order to represent all three models in determining the flow rates for the coming years (Table 6).
Table 6. Future projections, average of three models, repeated flow rate $\left(\mathrm{m}^{3} / \mathrm{s}\right)$

\begin{tabular}{ccccccc}
\hline \multirow{2}{*}{ Years } & \multicolumn{2}{c}{2050} & \multicolumn{2}{c}{2075} & \multicolumn{2}{c}{2100} \\
\cline { 2 - 7 } & RCP 4.5 & RCP 8.5 & RCP 4.5 & RCP 8.5 & RCP 4.5 & RCP 8.5 \\
\hline 2 & 36 & 35.7 & 33.8 & 34.1 & 32.7 & 32.9 \\
5 & 78.7 & 79.2 & 75.7 & 74.9 & 68.7 & 70.6 \\
10 & 136.1 & 137.9 & 127 & 126.4 & 112.5 & 116.3 \\
25 & 274.1 & 281.2 & 234.3 & 239.5 & 203.9 & 211.3 \\
50 & 453.7 & 471.3 & 353.1 & 372.4 & 305.4 & 317.5 \\
100 & 725.9 & 766.2 & 511.9 & 558.7 & 443 & 462.4 \\
500 & 1134.2 & 1201.1 & 778.2 & 857.8 & 671.7 & 701.9 \\
1000 & 1309.9 & 1388.3 & 892.9 & 986.6 & 770.2 & 805.1 \\
10000 & 1893.9 & 2010.4 & 1273.9 & 1414.6 & 1097.5 & 1147.8 \\
\hline
\end{tabular}

In the light of all these data obtained, a comparison analysis of the RCP 4.5 Scenario and the RCP 8.5 Scenario with the current situation was made.

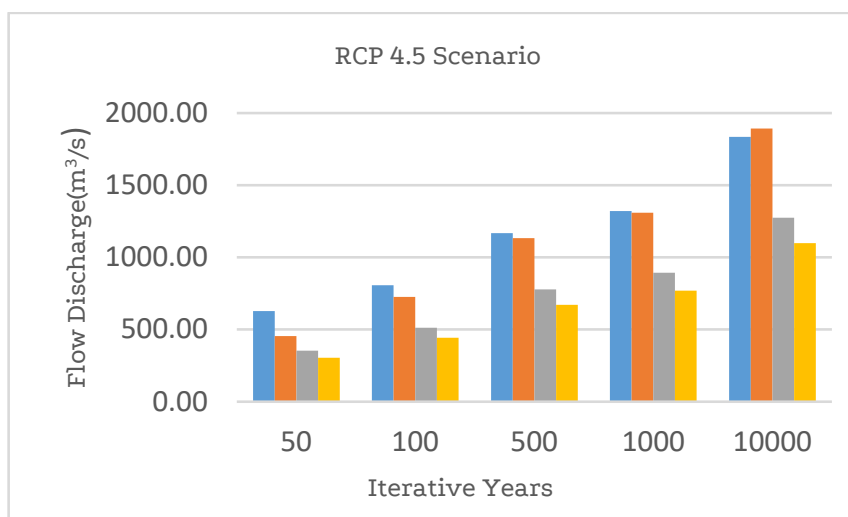

Current $\quad 2050$ RCP $4.5 \square 2075$ RCP $4.5 \square 2100$ RCP 4.5

Figure 4. A comparison analysis of the RCP 4.5 Scenario Results

In the RCP 4.5 scenario, it has been determined that the flood flow rates have increased compared to the current flow rates in the period until 2050, and there will be a slight decrease in the projections of 2075 and 2100.

In the RCP 8.5 scenario, it was determined that the 2050 projection was quite high compared to the flow rates currently calculated, and that there would be some decrease in the 2075 and 2100 projections. 


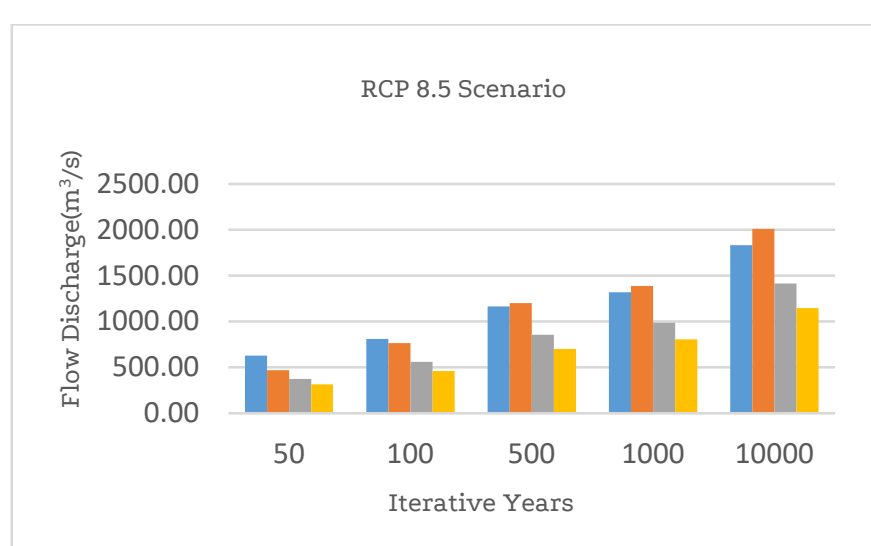

nCurrent 2050 RCP $8.5 \square 2075$ RCP $8.5 \square 2100$ RCP 8.5

Figure 5. A comparison analysis of the RCP 8.5 Scenario Results

In conclusion, flood discharges are determined to be a risk, especially according to the year 2050 project, when both scenarios are examined separately; calculations should be made by considering future discharges in the studies to be carried out in the basin. Otherwise, it should be taken into consideration that the floods that will occur in this basin may cause loss of life and property. Considering this study carried out in the basin, it was concluded that local governments should prepare flood scenarios.

\section{Declaration of Conflict of Interests}

The author(s) declare(s) that there is no conflict of interest. They have no known competing financial interests or personal relationships that could have appeared to influence the work reported in this paper.

\section{References}

[1.] IPCC, 2001.Third Assesment Report. Intergovernmental Panel on Climate

Change, http://www.ipcc.ch/activities/activities.shtml

[2.] Demir, V. and Kisi, Ö.2016. Flood Hazard Mapping by Using Geographic Information System and Hydraulic Model: Mert River, Samsun, Turkey, Hindawi Publishing Corporation Advances in Meteorology,4891015, p:9.

[3.] IPCC, 2007. Intergovernmental Panel on Climate Change (IPCC), 4.Report (AR4)

[4.] Demir, V. and Ulke Keskin, A. 2020. Obtaining the Manning roughness with terrestrial-remote sensing technique and flood modeling using FLO-2D: A case study Samsun from Turkey. Geofizika journal, 37-2.

[5.] IPCC, 2013. Climate Change 2013. The Physical Science Basis, http://www.ipcc.ch/report/ar5/wg1/

[6.] Sunde MG, He HS, Hubbart JA, Urban MA. Integrating downscaled CMIP5 data with a physically based hydrologic model to estimate potential climate change impacts on streamflow processes in a mixed-use watershed. Hydrol Process. 2017; 31(9):1790-803

[7.] Rummukainen M., 2010. State-of-the-art with regional climate models.
[8.] Ulke A, Beden N, Demir V \& Menek N 2017. Numerical modeling of Samsun Mert River floods. EWRA Publications, 57, 27-34.

[9.] Anonymous, 2021. Wikipedia web site. https://en.wikipedia.org/wiki/Antalya

[10.] Ozdemir, H. Applied Flood Hydrology. DSI Printing and PhotoFilm Operation Directorate Printing House, 81-94, Ankara, Turkey, 1978.

[11.] Bayazit, M., 1996. Probabilistic Methods in Civil Engineering, ITU, Faculty of Civil Engineering Printing House

[12.] Bayazit, M.1981. Statistical Methods in Hydrology, ITU, Technical University Printing House

[13.] Bayazit, M. and Onoz, B. 2008, Flood and Drought Hydrology, Nobel Publishing, 259, Istanbul.

[14.] Usul, N. 2008. Engineering Hydrology, ODTU Printing House, 408, Ankara.

[15.] Bayazit, M. and Yegen Oguz, E.B. 2013. Statistics for Engineers. Birsen Publishing 197, Istanbul.

[16.] Maidment, David R., editor in chief. 1993 Handbook of Hydrology, 17.1-17.53

[17.] Maidment, David R., editor in chief. 1993 Handbook of Hydrology, 18.1-18.65

[18.] Cetiner, H.I.., 2017. Modeling of Ergene Basin According to Taudem Algorithm with Computer Software and Comparison of the Results of Ova Stream by Calculating Flood Flows According to DSI Synthetic and Mockus Methods, 4. International Water Congress, 2-4 November 2017, Water Management in Smart Cities, 226-235, İzmir.

\section{How to Cite This Article}

Özkoca, T. and Ülke Keskin, A., Analysis of the Effect of Climate Change on Flood Flows of Kemer Ağva River, Antalya, Journal of Nature, Science \& Technology,1(2022), 6576.

https://doi.org/10.36937/janset.2022.6576 